\title{
Highly Sensitive Electrochemical Sensing Platform for the Detection of L-dopa Based on Electropolymerizing Glutathione Disulfide and Multi-walled Carbon Nanotube-modified Electrodes
}

\author{
Chengcheng Yang, Shu Zhu, Jiao Ma, Jinyi Song, Peiyao Ran and Yingzi Fu* $\mathbb{D D}^{\S}$ \\ Key Laboratory of Luminescence and Real-Time Analytical Chemistry (Southwest University), Ministry of Education, School of Chemistry and \\ Chemical Engineering, Southwest University, Chongqing 400715, China.
}

Received 25 February 2018, revised 12 November 2018, accepted 20 November 2018.

\begin{abstract}
A facile sensing platform for the detection of L-dopa has been developed by electropolymerizing glutathione disulfide (PGSSG) on the surface of glass carbon electrodes (GCE) which were modified by multi-walled carbon nanotubes (MWCNTs). The electrochemical behaviour of the proposed electrodes were investigated via cyclic voltammetry $(\mathrm{CV})$ and differential pulse voltammetry (DPV). The morphology of the PGSSG and PGSSG/MWCNTs were characterized by scanning electron microscopy (SEM). Under the optimized experimental conditions, the sensing platform showed the linear response to L-Dopa in a range from $1.0 \times 10^{-6}$ to $1.2 \times 10^{-3} \mathrm{M}$ with a detection limit of $3.3 \times 10^{-7} \mathrm{M}(\mathrm{S} / \mathrm{N}=3)$. Moreover, with the merits of high sensitivity and selectivity, good stability and reproducibility, the sensor was successfully applied for the determination of L-dopa in a real sample.
\end{abstract}

KEYWORDS

L-dopa, glutathione disulfide, multi-walled carbon nanotubes, electropolymerization, electrochemical determination.

\section{Introduction}

Parkinson's disease is a common degenerative disease of the nervous system, which is caused by serious shortage of dopamine in the brain. Although dopamine cannot be obtained by direct injection due to the existence of blood-brain barrier, levodopa (L-dopa) can penetrate the blood-brain barrier and convert into dopamine. ${ }^{1,2}$ On the basis of the foregoing, L-dopa can be used as a unique chiral drug for the treatment of Parkinson's disease. ${ }^{3}$ However, in the human body, L-dopa will produce a cytotoxic effect once the concentration exceeds $100 \mu \mathrm{M}$, such as nausea, vomiting, loss of appetite, insomnia and hallucinations. ${ }^{4-6}$ Therefore, developing an efficient and sensitive sensor for monitoring L-dopa in pharmaceutical and clinical procedures is urgent. Up to now, different techniques including spectrophotometry, ${ }^{7}$ high performance liquid chromatography, flow injection analysis, ${ }^{9}$ capillary zone electrophoresis and spectrofluorimetry have been utilized for the determination of L-dopa. ${ }^{10,11}$ These detection techniques often require complex equipment and the inspection processes are often cumbersome. Compared with these methods, the electrochemical methods have better performance because of their fast response, simple operation and low consumption of time.

Carbon nanotubes (CNTs) have attracted much attention on account of the outstanding chemical, mechanical and electrical properties, for instance, high mechanical strength, large surface areas, good electrical conductivity and durability under harsh conditions. ${ }^{12-16}$ Multiwalled carbon nanotubes (MWCNTs), as one kind of CNTs, have been extensively applied to modify electrodes owing to the advantages of simplicity, high selectivity, high sensitivity and stability. ${ }^{17}$ And MWCNTs have been testified to feature strong electrocatalytic activity for some important

* To whom correspondence should be addressed. E-mail: fyzc@ swu.edu.cn biomolecules, such as cytochrome c, nicotinamide adenine dinucleotide, hydrogen peroxide and catecholamines. ${ }^{18-21}$ Thus, the material in combination with MWCNTs and conductive polymer is promising for the detection of L-dopa. ${ }^{22,23}$

Glutathione disulfide (GSSG) is a tripeptide with a gamma peptide linkage between the carboxyl group of the glutamate side-chain and the amine group of cysteine. It can be electropolymerized on the surface of GCE to promote electron transfer. ${ }^{24}$ The application of the polymerized glutathione disulfide (PGSSG) in electroanalysis is rarely reported. Hence, based on electropolymerization of GSSG and MWCNTs modified GCE, a strategy for the simple and rapid detection of L-dopa has been designed. With the high electroactive surface area and excellent electrical conductivity, the PGSSG and MWCNT modified sensing platform exhibited high sensitivity and wide linear range for the measurement of L-dopa, and achieved sensitive detection of L-dopa in actual samples.

\section{Experimental}

\subsection{Materials and Reagents}

Glutathione disulfide (GSSG, 98 \%), levodopa (L-dopa, 98 \%), ascorbic acid (AA, $99 \%$ ) were purchased from Aladdin Chemistry Co. Ltd. (Shanghai, China). Multi-walled carbon nanotubes (MWCNTs, 10-20 nm in diameter, length of $30 \mu \mathrm{m}$ ) were bought from Sigma Chemical Co. (St. Louis, MO, U.S.A.). 0.1 M phosphate buffer solution (PBS) was prepared by $\mathrm{Na}_{2} \mathrm{HPO}_{4}$ and $\mathrm{KH}_{2} \mathrm{PO}_{4}$, containing $0.1 \mathrm{M} \mathrm{KCl}$ as supporting electrolyte. $5.0 \mathrm{mM}$ $\left[\mathrm{Fe}(\mathrm{CN})_{6}\right]^{4-/ 3-}$ solution was prepared with $\mathrm{K}_{4} \mathrm{Fe}(\mathrm{CN})_{6}$ and $\mathrm{K}_{3} \mathrm{Fe}(\mathrm{CN})_{6}$ containing $0.1 \mathrm{M}$ PBS. All chemicals were of analytical grade and used without further purification. Double-distilled water was used throughout the experiments, which was prepared by a Millipore system. 

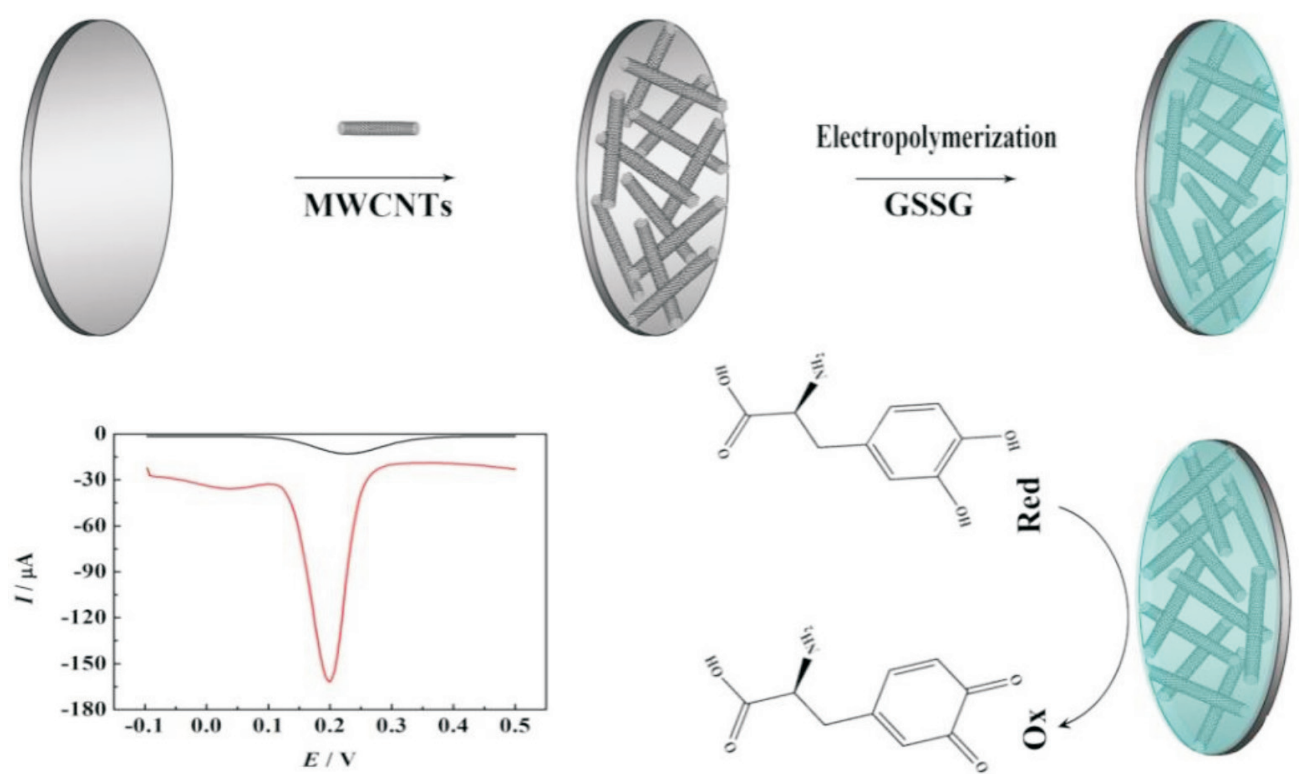

Scheme 1

Procedure for the preparation of PGSSG/MWCNTs/GCE.

\subsection{Apparatus}

Cyclic voltammetry (CV) and differential pulse voltammetry (DPV) measurements were performed on CHI440A electrochemical workstation (Shanghai Chenhua Instruments Co., China). The conventional three-electrode system consists of the working electrode (glass carbon electrodes, GCEs, $\Phi=4 \mathrm{~mm}$ ), the counter electrode (platinum wire) and the reference electrode (saturated calomel electrode, SCE). The morphology of different modified electrodes was characterized by scanning electron microscope (SEM, S-4800, Hitachi). All experiments were carried out at room temperature $\left(25 \pm 0.5^{\circ} \mathrm{C}\right)$.

\subsection{Preparation of the Modified Electrodes}

Prior to modification, the GCEs were polished sequentially with 1.0, 0.3 and $0.05 \mu \mathrm{m}$ alumina slurry and rinsed thoroughly with double-distilled water in each polishing step. Then they were sonicated in alcohol and double-distilled water successively, and dried at room temperature for further use. Subsequently, $10 \mu \mathrm{L}$ of MWCNTs solution $\left(0.5 \mathrm{mg} \mathrm{mL}^{-1}\right)$ were dropped onto the glassy carbon electrodes and dried at room temperature (MWCNTs/GCEs). Finally, the MWCNTs/GCEs were immersed into $3 \mathrm{~mL}$ PBS containing $5 \mathrm{mM}$ GSSG (pH 7.0) to electrolytic deposition for 10 cycles of cyclic voltammetry (PGSSG/MWCNTs/GCEs).

The preparation process of PGSSG/MWCNTs/GCE is shown in Scheme 1.

\section{Results and Discussion}

3.1. Preparation and Characterization of Modified Electrodes

Figure 1 displays the cyclic voltammograms $(\mathrm{CVs})$ of the electropolymerization process of GSSG. Two anodic peaks and one cathodic peak were observed at the potential of $+1.38 \mathrm{~V}$, $+1.57 \mathrm{~V}$ and $-0.56 \mathrm{~V}$, respectively. The peak currents gradually increased from 0.98 to $1.34 \mathrm{~mA}$ with the increasing of scanning cycles, indicating the continuous growth of the PGSSG film. After 10 cycles, the peak currents tended to stabilize. The formation of PGSSG film is due to the oxidization of amino of GSSG to generate $\alpha$-amino free radical at higher positive potential, which can link with the carboxyl of MWCNTs. ${ }^{24}$

The surface morphologies of MWCNTs and PGSSG/MWCNTs

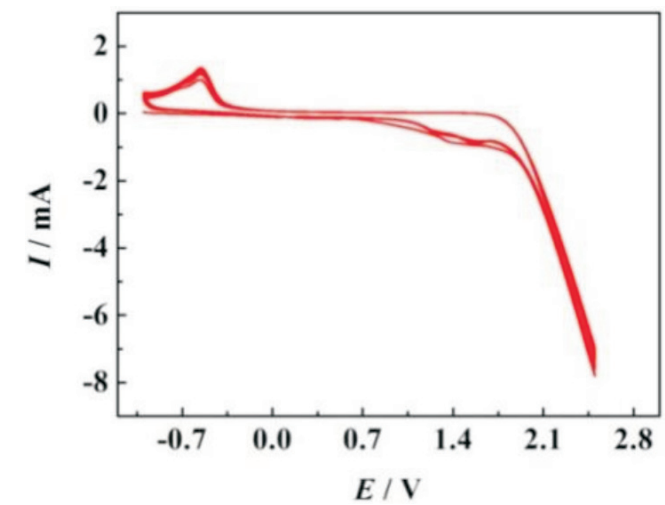

Figure 1 The electropolymerization of MWCNTs/GCE in 5 mM GSSG solution via $\mathrm{CV}$ (potential range: -1.0 to $+2.5 \mathrm{~V}$; scan rate: $100 \mathrm{mV} \mathrm{s}^{-1)}$.

were characterized by scanning electron microscopy (SEM). MWCNTs presented a network structure (Fig. 2A). After glutathione disulfide was electropolymerized on MWCNTs, the porous grain film was observed with the disappearance of network structure (Fig. 2B).

\subsection{Electrochemical Behaviour of the Modified Electrodes}

Cyclic voltammetry (CV) was chosen to investigate the electrochemical properties of the differently modified electrodes in $5.0 \mathrm{mM}\left[\mathrm{Fe}(\mathrm{CN})_{6}\right]^{4 / 3-}$ solution $(\mathrm{pH} 7.0)$ at a scan rate of $100 \mathrm{mV} \mathrm{s}^{-1}$. From Fig. 3A, a pair of reversible redox peaks were discovered on bare GCE (curve a). The increased peak currents were obtained on MWCNTs/GCE (curve b), PGSSG/GCE (curve c) and PGSSG/ MWCNTs/GCE (curve d), indicating that the electron transfer was promoted by MWCNTs and PGSSG. The effective electroactive surface area of PGSSG/MWCNTs/GCE was calculated by the Randles-Sevcik equation (Equation 1) under the supposition of diffusion-controlled. ${ }^{25}$

$$
I_{p}=2.69 \times 10^{5} A D^{1 / 2} n^{3 / 2} v^{1 / 2} C
$$

where $I_{p}$ is the redox peak current, $n$ is the number of electrons transfer in the reaction (for $\left[\mathrm{Fe}(\mathrm{CN})_{6}\right]^{4-3-}, n=1$ ), $A$ is the effective surface area $\left(\mathrm{cm}^{2}\right)$ of the modified electrodes, $D$ is diffusion coefficient of $\left[\mathrm{Fe}(\mathrm{CN})_{6}\right]^{4-/ 3-}$ (equal to $\left.6.70 \times 10^{-6} \mathrm{~cm}^{2} \mathrm{~s}^{-1}\right)$, $v$ is the sweep 
A

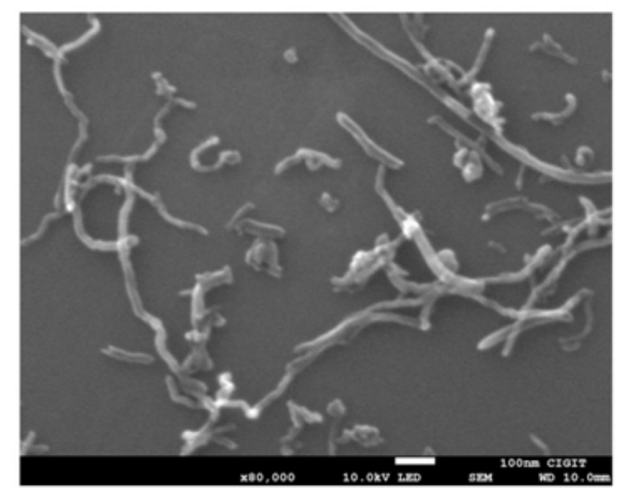

Figure 2 SEM images of (A) MWCNTs and (B) PGSSG/MWCNTs.

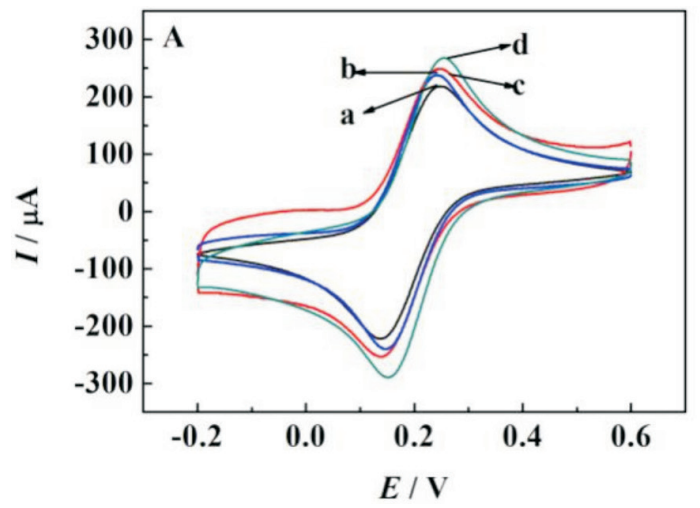

B

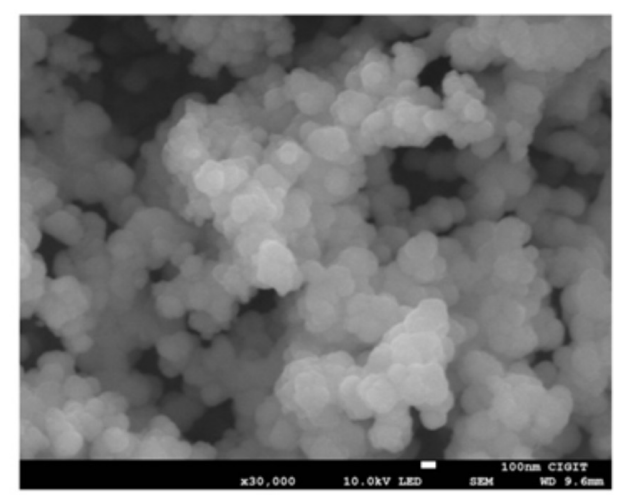

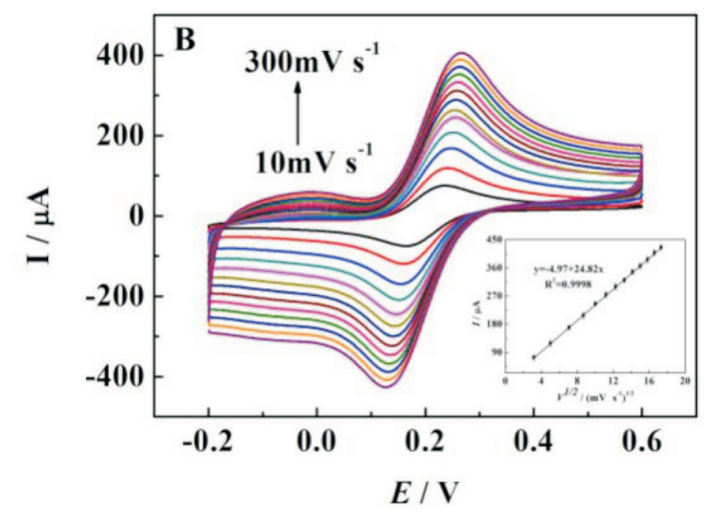

Figure 3 (A) CVs of different modified electrodes in $5.0 \mathrm{mM}\left[\mathrm{Fe}(\mathrm{CN})_{6}\right]^{4 / 3-}$ : (a) bare GCE, (b) MWCNTs/GCE, (c) PGSSG/MWCNTs/GCE and (d) PGSSG/MWCNTs/GCE. (B) CVs of PGSSG/WMCNTs/GCE in $5.0 \mathrm{mM}\left[\mathrm{Fe}(\mathrm{CN})_{6}\right]^{4 / 3-}$ at different scan rates: 10, 25, 50, 75, 100, 125, 150, 175, 200, 225, $250,275,300 \mathrm{mV} \mathrm{s}^{-1}$ (Inset: the calibration plot for the anodic peak currents $v s$. the square root of scan rate).

rate $\left(\mathrm{V} \cdot \mathrm{s}^{-1}\right)$ and $c$ is the concentration of $\left[\mathrm{Fe}(\mathrm{CN})_{6}\right]^{4-13-}$. The $\mathrm{CVs}$ at different scan rates were obtained in $5.0 \mathrm{mM}\left[\mathrm{Fe}(\mathrm{CN})_{6}\right]^{4-13-}$. According to the slope of $I_{p} v s . v^{1 / 2}$ (Fig. 3B), the effective electroactive surface areas of bare GCE and PGSSG/MWCNTs/GCE were calculated to be 0.125 and $0.225 \mathrm{~cm}^{2}$, respectively.

\subsection{Effect of $\mathrm{pH}$ Values}

The $\mathrm{pH}$ of the sample is an important factor in electrochemical reactions. The influence of the $\mathrm{pH}$ in the range from 5.0 to 7.5 for current responses and anodic peak potentials of L-dopa has been investigated via DPV. As shown in Fig. 4, the peak currents increased with the increasing $\mathrm{pH}$ until 6.0 (Fig. 4A and Fig. 4B(a). The peak potential $\left(E_{p}\right)$ shifted negatively with the increasing $\mathrm{pH}$ (Fig. 4B(b)), and presented a linear relationship to $\mathrm{pH}$ value. The regression equation is $E_{p}=0.6352-0.0729 \mathrm{pH}\left(\mathrm{R}^{2}=0.9896\right)$. The changes of current responses and anodic peak potentials were due to the participation of protons in the electrode reaction process. ${ }^{26}$

\subsection{Electrochemical Interaction between PGSSG/MWCNTs and L-dopa}

$\mathrm{CV}$ measurements were used to investigate the electrochemical behaviour of modified electrodes in $0.5 \mathrm{mM} \mathrm{L-dopa} \mathrm{(pH} \mathrm{6.0)}$ at the scan rate of $100 \mathrm{mV} \mathrm{s}^{-1}$. From Fig. 5A, the increasing anodic and cathodic peak currents were observed on bare GCE, MWCNTs/GCE, PGSSG/GCE and PGSSG/MWCNTs/GCE, gradually. Compared with bare GCE, the maximum peak current and the smaller potential difference $\left(\Delta E_{p=} E_{p a}-E_{p c}\right)$ was acquired on
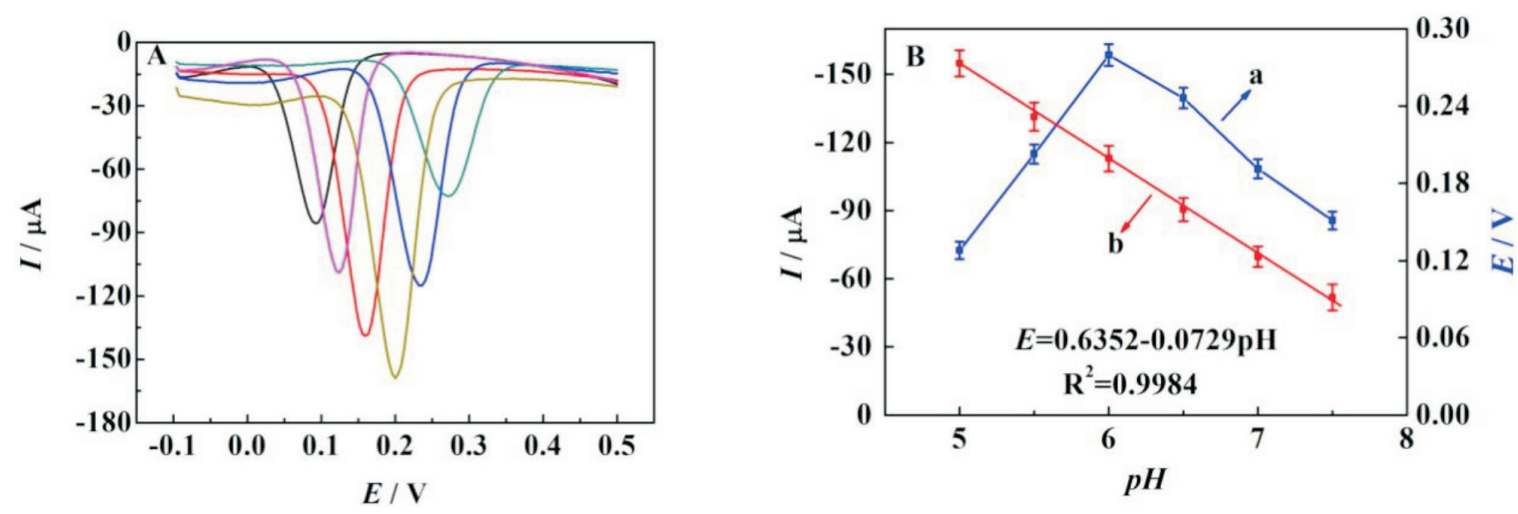

Figure 4 (A) DPV of the PGSSG/MWCNTs/GCE in $0.5 \mathrm{mM} \mathrm{L-dopa} \mathrm{with} \mathrm{different} \mathrm{pH}(5.0,5.5,6.0,6.5,7$ and 7.5$)$. (B) The effect of pH to current responses and anodic peak potentials. 

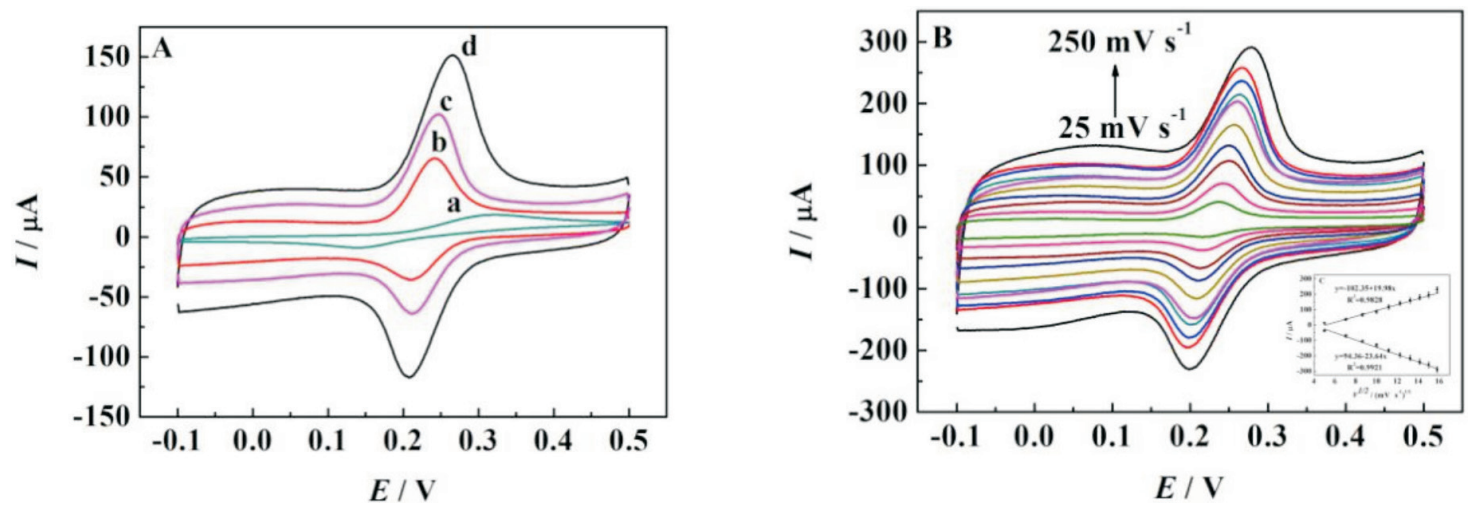

Figure 5 (A) CVs of (a) GCE, (b) MWCNTs/GCE, (c) PGSSG/GCE and (d) PGSSG/MWCNTs/GCE in 0.1 M PBS (pH 6.0) containing 0.5 mM L-dopa. (B) CVs of PGSSG/MWCNTs/GCE in $0.5 \mathrm{mM} \mathrm{L-dopa} \mathrm{(pH} \mathrm{6.0)} \mathrm{at} \mathrm{different} \mathrm{scan} \mathrm{rates} \mathrm{Inset:} \mathrm{linear} \mathrm{relationship} \mathrm{between} \mathrm{the} \mathrm{peak} \mathrm{currents} \mathrm{and} \mathrm{the}$ square root of scan rate.

PGSSG/MWCNTs/GCE (Fig. 5A(d)), hinting the electron transfer was promoted by the synergistic effect of MWCNTs and PGSSG. ${ }^{27}$

The kinetics process of the redox of L-dopa on the surfaces of the modified electrode was further investigated via $\mathrm{CV}$ at scan rates from 25 to $250 \mathrm{mV} \mathrm{s}^{-1}$. The peak currents increased with the increase of scan rates, and the results showed the linear relationship between peak currents $\left(I_{p a}\right.$ or $\left.I_{p c}\right)$ and the square-root of scan rate $\left(v^{1 / 2}\right)$ (Fig. $\left.5 \mathrm{~B}\right)$. The corresponding linear regression equations are expressed as $I_{p a}=94.36-23.64 v^{1 / 2}\left(\mathrm{R}^{2}=0.9921\right)$ and $I_{p c}=$ $-102.35+19.98 v^{1 / 2}\left(R^{2}=0.9828\right)$, revealing the electrocatalytic process was controlled by diffusion on PGSSG/MWCNTs/GCE. ${ }^{28}$

\subsection{Electrochemical Detection of L-dopa}

Differential pulse voltammetry (DPV) with high sensitivity and resolution was employed to efficiently analyze the L-dopa at low concentration (potential range: 0.0 to $+0.5 \mathrm{~V}$, amplitude: $50 \mathrm{mV}, \mathrm{pH}$ 6.0). ${ }^{27,}{ }^{29}$ The anodic peak currents are linearly enhanced with the increasing concentration of L-dopa from

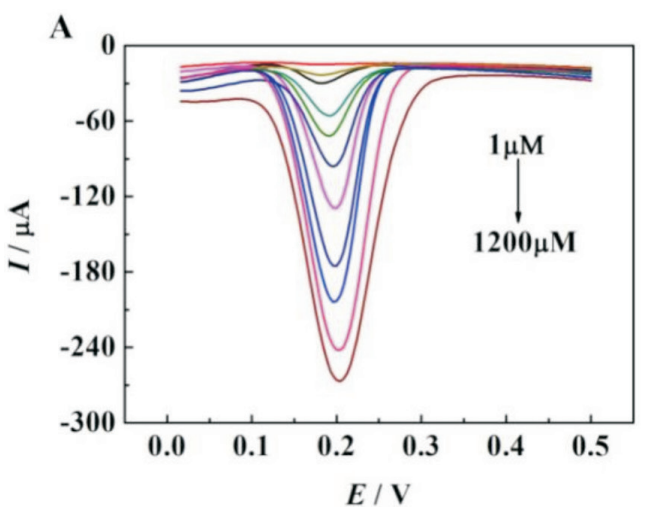

$1.0 \times 10^{-6}$ to $1.2 \times 10^{-3} \mathrm{M}$ (Fig. $6 \mathrm{~A}$ ). The calibration plots are illustrated in Fig. $6 \mathrm{~B}$, and the peak currents are in proportion to the concentrations of the L-dopa in two ranges (due to kinetic limitation) ${ }^{30,31}$ The first range is from $1.0 \times 10^{-6}$ to $1.5 \times 10^{-4} \mathrm{M}$, with a corresponding equation of $I_{p}(\mu \mathrm{A})=-9.76-0.55 c(\mu \mathrm{M})\left(\mathrm{R}^{2}=\right.$ $0.9742)$. The second range is from $1.5 \times 10^{-4}$ to $1.2 \times 10^{-3} \mathrm{M}$ with the regression equation of $I_{p}(\mu \mathrm{A})=-94.95-0.15 c(\mu \mathrm{M})\left(\mathrm{R}^{2}=\right.$ $0.9778)$. The detection limit is $3.3 \times 10^{-7} \mathrm{M}(\mathrm{S} / \mathrm{N}=3)$. Moreover, the comparison between the proposed sensing platform and previous methods for determination of L-dopa is presented in Table 1 . And a relatively wider linear range and a relatively lower detection limit of the PGSSG/MWCNTs/GCE is observed.

\subsection{Interference Study}

Ascorbic acid (AA) is an electroactive molecule, which can be oxidized at the approximate potential of L-dopa on the conventional electrode. AA usually coexists with L-dopa in biological fluids, so it become a common interference to the determination of L-dopa. As shown in Fig. 7A, L-dopa and AA were oxidized to

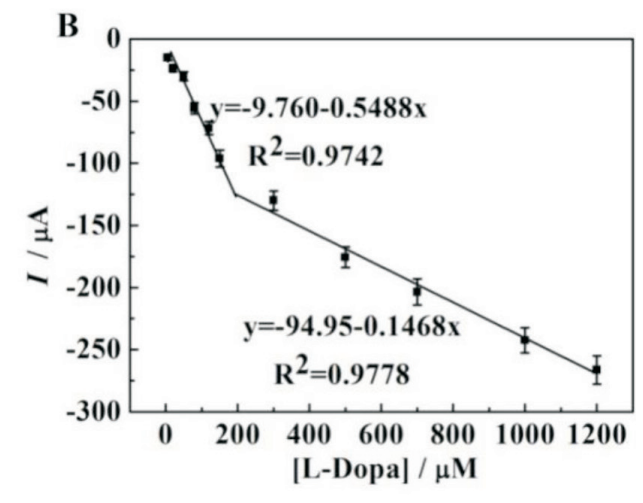

Figure 6 (A) DPV of the PGSSG/MWCNTs/GCE in L-Dopa (the concentrations from $1.0 \times 10^{-6}$ to $1.2 \times 10^{-3} \mathrm{M}$, pH 6.0). (B) Calibration plots of the anodic peak currents vs. concentrations of L-dopa.

Table 1 Comparison of the proposed sensing platform with other electrochemical methods for determination of L-dopa.

\begin{tabular}{lccc}
\hline Modified electrode & Detection method & LOD/M & Linear range/M \\
\hline Gr-GCE & DPV & $8.0 \times 10^{-7}$ & $1.0 \times 10^{-6}-1.4 \times 10^{-5}$ \\
CYN/MWCNT/GCE & DPV & $3.6 \times 10^{-7}$ & $1.0 \times 10^{-6}-1.0 \times 10^{-4}$ \\
PCA/GCE & SWV & $1.4 \times 10^{-7}$ & $1.0 \times 10^{-6}-5.0 \times 10^{-5}$ \\
SWCNT/GC & DPV & $3.0 \times 10^{-7}$ & $5.0 \times 10^{-7}-2.0 \times 10^{-5}$ \\
PG/ZnO/CNTs/CPE & DPV & $8.0 \times 10^{-8}$ & $5.0 \times 10^{-6}-5.0 \times 10^{-4}$ \\
rGO-GCE & DPV & $1.1 \times 10^{-6}$ & $2.0 \times 10^{-6}-1.0 \times 10^{-4}$ \\
PGSSG/MWCNT/GCE & DPV & $3.3 \times 10^{-7}$ & $1.0 \times 10^{-6}-1.2 \times 10^{-3}$ \\
\hline
\end{tabular}



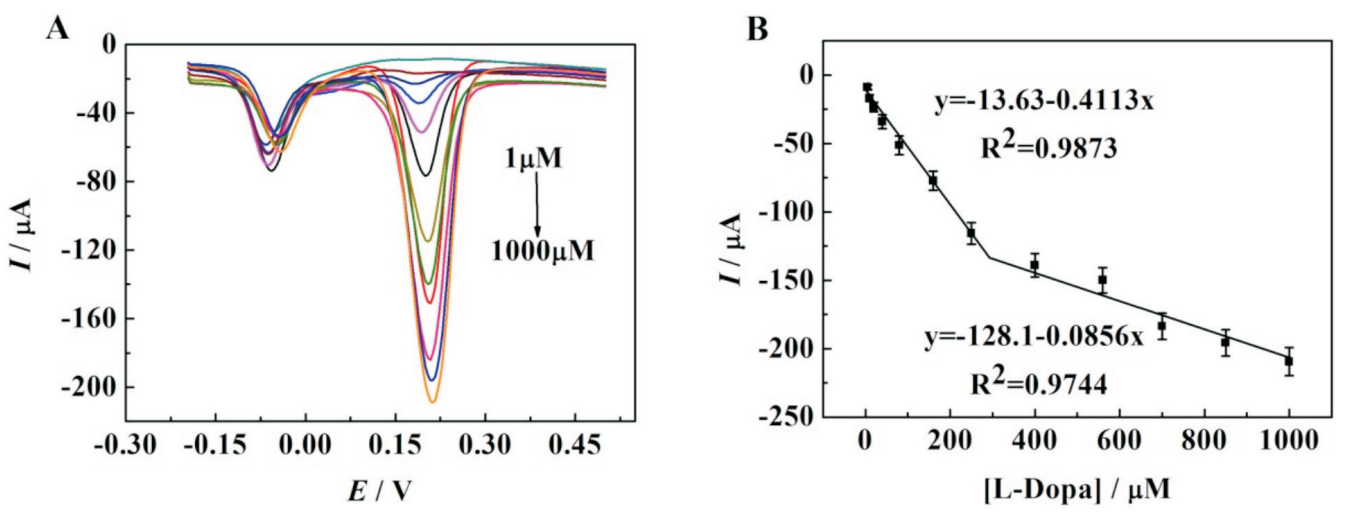

Figure 7 (A) DPV of the PGSSG/MWCNTs/GCE in different concentrations of L-Dopa (pH 6.0) in the presence of 1.0 mM AA. (B) Calibration plots of the oxidation peak current $v$ s. the concentration of L-dopa.

form two different sharp and well defined peaks at $0.03 \mathrm{~V}$ and $0.18 \mathrm{~V}$, respectively. In the presence of $1.0 \mathrm{mM} \mathrm{AA}$, the anodic peak current of L-dopa increased with increasing concentration and exhibited two segments with different linear relationships (Fig. 7B). The corresponding equations are $I_{p}(\mu \mathrm{A})=-13.63-0.41 \mathrm{c}$ $(\mu \mathrm{M})\left(\mathrm{R}^{2}=0.9873\right)$ from the concentration of $1.0 \times 10^{-6}$ to $2.5 \times$ $10^{-4} \mathrm{M}$ and $I_{p}(\mu \mathrm{A})=-128.08-0.08 c(\mu \mathrm{M})\left(\mathrm{R}^{2}=0.9744\right)$ from the concentration of $2.5 \times 10^{-4}$ to $1.0 \times 10^{-3} \mathrm{M}$, respectively. The results suggested this sensing platform can be used for selective determination of L-dopa.

The potential interference of some substances were also investigated. DPV response of $50.0 \mu \mathrm{M}$ L-dopa ( $\mathrm{pH}$ 6.0) were individually measured in the presence of the interfering substances. The limited tolerance was defined as the ratio of maximum concentration of the interfering substances that caused approximate $5 \%$ of the relative standard deviation (RSD) to the concentration of L-dopa. Table 2 shows that the oxidation peak currents of L-dopa were not affected by the conventional cations, anions and organic substances, indicating the sensing platform possessed a good selectivity.

\subsection{Real Sample Analysis}

In order to evaluate the practical applicability of the proposed sensing platform, the analysis of real samples was carried out. The urine samples were adopted in the experiments using the standard addition method under optimum conditions. They were diluted 10 times with $0.1 \mathrm{M} \mathrm{PBS}$ ( $\mathrm{pH}$ 6.0) prior to measurement and spiked with specified amounts of L-dopa. The results are shown in Table 3, the recoveries of the spiked samples were in the range of 98.0-102.0\% with RSD less than $2.8 \%$, displayed an acceptable accuracy of PGSSG/MWCNTs/GCE for the determination of L-dopa in real samples.

\subsection{Reproducibility and Stability}

The reproducibility of the PGSSG/MWCNTs/GCE was evaluated by using six repetitive DPVs determination of $0.5 \mathrm{mM}$

Table 2 Interference of some coexisting substances for $50.0 \mu \mathrm{ML}$-dopa.

Interfering substances Tolerant limit $\left(c_{\text {Substance }} / c_{\mathrm{L}-\text { dopa }}\right)$

$\mathrm{Na}^{+}, \mathrm{K}^{+}, \mathrm{Ca}^{2+}, \mathrm{Cl}^{-}, \mathrm{Mg}^{2+}, \mathrm{Co}^{2+}, \mathrm{Ni}^{2+}$,

$\mathrm{Zn}^{2+}, \mathrm{SO}_{4}^{2-}, \mathrm{NH}^{4+}, \mathrm{F}^{-}$

Glucose

180.0

Histidine, glutamic acid, alanine,

100.0

glycine, phenylalanine

Uric acid
Table 3 Determination of L-dopa in real samples $(n=6)$.

\begin{tabular}{lcccc}
\hline Samples & $\begin{array}{c}\text { Added } \\
/ \mu \mathrm{M}\end{array}$ & $\begin{array}{c}\text { Found } \\
/ \mu \mathrm{M}\end{array}$ & $\begin{array}{c}\text { Recovery } \\
/ \%\end{array}$ & $\begin{array}{c}\text { RSD } \\
/ \%\end{array}$ \\
\hline Urine & 5.0 & 4.9 & 98.0 & 2.2 \\
& 15.0 & 15.3 & 102.0 & 1.9 \\
& 45.0 & 45.2 & 100.4 & 2.8 \\
\hline
\end{tabular}

L-dopa. The RSD was gained to be $4.6 \%$, indicating the modified electrodes exhibited good reproducibility attribute to the robust and stable of the PGSSG/MWCNT/GCEs. The long-term stability of the constructed electrodes was also investigated by storing them at $4{ }^{\circ} \mathrm{C}$ for 3 weeks. Compared with the initial current, the acquired peak currents decreased less than $5.8 \%$, demonstrating that the assay exhibited acceptable stability and durability.

\section{Conclusion}

In this work, a simple and efficient sensing platform based on the modification of PGSSG and MWCNTs was developed for the sensitive and selective detection of L-dopa. The results displayed a wide linear dynamic range for sensing applications with a detection limit of $0.33 \mu \mathrm{M}$ and it can be used to detect L-dopa in real samples sensitively. This not only developed a method for the determination of L-dopa, but also opened a new avenue for the sensitive sensing of electroactive biomolecules.

\section{Acknowledgement}

The authors gratefully appreciate the financial support provided by the National Natural Science Foundation of China (21272188).

\section{${ }^{5}$ ORCID ID}

Y. Fu: (iD) orcid.org/0000-0003-4280-1159

\section{References}

1 W. Dauer and S. Przedborski, Parkinson's disease: mechanisms and models, Neuron, 2003, 39, 889.

2 W.M. Pardridge, Blood-brain barrier delivery, Drug Discovery Today, 2007, 12(1): 54-61.

3 S.P. Khor and A. Hsu, The pharmacokinetics and pharmacodynamics of levodopa in the treatment of Parkinson's disease, Curr. Clin. Pharmacol., 2007, 2(3), 234.

4 R. Katzenschlager and A. J. Lees, Treatment of Parkinson's disease: levodopa as the first choice, J. Neurol., 2002, 249, 19-24.

5 L.V. Laitinen, A.T. Bergenheim and M.I. Hariz, Leksell's posteroventral pallidotomy in the treatment of Parkinson's disease, J. Neurosurg. 1992, 76, 53.

6 C.M. Jin, Y.J. Yang, H.S. Huang, et al. Mechanisms of L-DOPAinduced cytotoxicity in rat adrenal pheochromocytoma cells: impli- 
cation of oxidative stress-related kinases and cyclic AMP, Neuroscience, 2010, 170(2), 390-398.

7 B.A. Hasan, K.D. Khalaf and M. De La Guardia, Flow analysisspectrophotometric determination of l-dopa in pharmaceutical formulation by reaction with p-aminophenol, Talanta, 1995, 42, 627.

8 P. Siddhuraju and K. Becker, Rapid reversed-phase high performance liquid chromatographic method for the quantification of L-Dopa (L-3,4-dihydroxyphenylalanine), non-methylated and methylated tetrahydroisoquinoline compounds from Mucuna beans, Food Chem., 2001, 72, 389.

9 L.H. Marcolino-Junior, M.F. Teixeira and A.V. Pereira and O. FatibelloFilho, Flow injection determination of levodopa in tablets using a solid-phase reactor containing lead (IV) dioxide immobilized, J. Pharm. Biomed. Anal., 2001, 25(3), 393.

10 S. Zhao, W. Bai, B. Wang and M. He, Determination of levodopa by capillary electrophoresis with chemiluminescence detection, Talanta, $2007,73,142$.

11 T. Madrakian, A. Afkhami and M. Mohammadnejad, Simultaneous spectrofluorimetric determination of levodopa and propranolol in urine using feed-forward neural networks assisted by principal component analysis, Talanta, 2009, 78(3), 1051.

12 M. Gara and R.G. Compton, Activity of carbon electrodes towards oxygen reduction in acid: a comparative study, New J. Chem., 2011,35, 2647-2652.

13 V. Vamvakaki, K. Tsagaraki and N. Chaniotakis, Carbon nanofiberbased glucose biosensor, Anal. Chem., 2006, 78, 5538-5542.

14 H.X. Luo, Z.J. Shi, N.Q. Li, Z.N. Gu and Q.K. Zhuang, Investigation of the electrochemical and electrocatalytic behavior of single-wall carbon nanotube film on a glassy carbon electrode, Anal. Chem., 2001, 73(5), 915-920.

15 X.P. Hao, S.G. Chen, W.H. Wang, Z.Q. Yang, L.F. Yue, H.Y. Sun and F. Cheng, AgNP-coordinated glucosamine-grafted carbon nanotubes with enhanced antibacterial properties, New J. Chem., 2017, 41, 7045-7051.

16 Y. Ni, H. Liu, J. Xu, Y. Yue and S.J. Shao, Construction of a selective electrochemical sensing solid-liquid interface for the selective detection of fluoride ion in water with bis(indolyl)methane-functionalized multi-walled carbon nanotubes, New J. Chem., 2017, 41, 14246-14252.

17 R. Prasad and B.R. Bhat, Self-assembly synthesis of $\mathrm{Co}_{3} \mathrm{O}_{4} /$ multiwalled carbon nanotube composites: an efficient enzyme-free glucose sensor, New J. Chem., 2015, 39, 9735-9742.

18 J.J. Davis, R.J. Coles and H.A. Hill, Protein electrochemistry at carbon nanotube electrodes, J. Electroanal. Chem., 1997, 440, 279-282.

19 M. Musamech, J. Wang, A. Merkoci and Y. Lin, Low-potential stable $\mathrm{NADH}$ detection at carbon-nanotube-modified glassy carbon electrodes, Electrochem. Comm., 2002, 4, 743-746.

$20 \mathrm{~J}$. Wang and M. Musameh, Carbon nanotube/teflon composite electrochemical sensors and biosensors, Anal. Chem., 2003, 75, 2075-2079.

$21 \mathrm{H}$. Luo, Z. Shi, N. Li, Z. Gu and Q. Zhuang, Investigation of the electrochemical and electrocatalytic behavior of single-wall carbon nanotube film on a glassy carbon electrode, Anal. Chem., 2001, 73, 915-920.

22 R. Ramkumar and M.M. Sundaram, Electrochemical synthesis of polyaniline cross-linked NiMoO 4 nanofibre dendrites for energy storage devices, New J. Chem., 2016, 40, 7456-7464.

23 D.M. Guo, Y.H. Huang, C. Chen, Y. Chen and Y.Z. Fu, A sensing inter- face for recognition of tryptophan enantiomers based on porous cluster-like nanocomposite films, New J. Chem., 2014, 38, 5880-5885.

24 Q. Xia, X. Lin, C.C. Yang, J. Ma and Y.Z. Fu, The application of poly (glutathione disulfide)-poly (L-lysine) multilayer films for the enantioselective interaction with ascorbic acid and isoascorbic acid, $J$. Electrochem. Soc., 2016, 163(14), 744-750.

25 H.Y. Yue, H. Zhang, S. Huang, X.Y. Lin, X. Gao, J. Chang, L.H. Yao and E.J. Guo, Synthesis of $\mathrm{ZnO}$ nanowire arrays/3D graphene foam and application for determination of levodopa in the presence of uric acid, Biosens. Bioelectron., 2017, 89, 592-597.

26 M. Fouladgar, H. Karimi-Maleh and V.K. Gupta, CoFe2O4@ TiO2 decorated reduced graphene oxide nanocomposite for photocatalytic degradation of chlorpyrifos, J. Mol. Liq., 2015, 208, 122-129.

27 A. Afkhami, F. Kafrashi and T Madrakian, Electrochemical determination of levodopa in the presence of ascorbic acid by polyglycine/ZnO nanoparticles/multi-walled carbon nanotubesmodified carbon paste electrode, Ionics, 2015, 21(10), 2937-2947.

28 Z.Y. Yang, C.C. Qi, X.H. Zheng and J.H. Zheng, Facile synthesis of silver nanoparticle-decorated graphene oxide nanocomposites and their application for electrochemical sensing, New J. Chem., 2015, 39, 9358-9326.

29 M.A. Kamyabi and N. Rahmanian, An electrochemical sensing method for the determination of levodopa using a poly (4-methylortho-phenylenediamine)/MWNT modified GC electrode, Anal. Methods, 2015, 7, 1339-1348.

30 H. Beitollahi, J. Raoof and R. Hosseinzadeh, Application of a carbonpaste electrode modified with 2,7-bis(ferrocenyl ethyl)fluoren-9-one and carbon nanotubes for voltammetric determination of levodopa in the presence of uric acid and folic acid, Electroanalysis, 2011, 23(8), 1934-1940.

31 S.Y. Yi, J.H. Lee and H.G. Hong, A selective determination of levodopa in the presence of ascorbic acid and uric acid using a glassy carbon electrode modified with reduced graphene oxide, J. Appl. Electrochem., 2014, 44, 589-597.

32 Q. Wang, M.R. Das, M. Li, R. Boukherroub and S. Szunerits, Voltammetric detection of 1-dopa and carbidopa on graphene modified glassy carbon interfaces, Bioelectrochemistry, 2013, 93, 15-22.

33 M. Amiri-Aref, J.B. Raoof and R. Ojani, Utilization of a bioactive anthocyanin for the fabrication of a novel carbon nanotube-based electrochemical sensor and its electrocatalytic properties for selective determination of 1-dopa in the presence of uric acid, Ionics, 2016, 22, $125-134$.

34 A. Rohanifar, A.M. Devasurendra, J.A. Young and J.R. Kirchhoff, Determination of L-DOPA at an optimized poly (caffeic acid) modified glassy carbon electrode, Anal. Methods, 2016, 8(44), 7891-7897.

35 S.A. Wring and J.P. Hart, Chemically modified, carbon-based electrodes and their application as electrochemical sensors for the analysis of biologically important compounds: a review, Analyst, 1992, 117, 1215-1229.

36 A. Afkhami, F. Kafrashi and T. Madrakian, Electrochemical determination of levodopa in the presence of ascorbic acid by polyglycine/ZnO nanoparticles/multi-walled carbon nanotubes-modified carbon paste electrode, Ionics, 2015, 21, 2937-2947.

37 S.Y. Yi, J.H. Lee and H.G. Hong, A selective determination of levodopa in the presence of ascorbic acid and uric acid using a glassy carbon electrode modified with reduced graphene oxide, J. Appl. Electrochem., 2014, 44, 589-597. 